\section{Grape Phylloxera Gallicole and Radicicole Activity on Grape Rootstock Vines}

Jeffrey Granett ${ }^{1}$

Entomology Department, University of California, One Shields Avenue Davis, CA 95616

Laszlo Kocsis

Department of Horticulture, Georgikon Faculty of Agronomy, University of Veszprém, H-8360 Keszthely, Deak F. u 16, Hungary

Laszlo Horvath

Deceased, Department of Entomology, Georgikon Faculty of Agronomy, University of Veszprém, Keszthely, Hungary

\section{Eva Baracsi Horvathne}

Department of Horticulture, Georgikon Faculty of Agronomy, University of Veszprém, H-8360 Keszthely, Deak F. u 16, Hungary

Additional index words. Daktulosphaira vitifoliae, leaf galls, root galls, Vitis, rootstock

Abstract. The objective was to explore temporal distribution of grape phylloxera, Daktulosphaira vitifoliae (Fitch), gallicoles on grapevine rootstocks (Vitis sp.) and determine how this distribution arose. We tested the hypothesis that leaf galls are created by individuals arising from the soil in the spring. Galls begin to appear at budbreak and gall averages per leaf increase variably as the season progresses. Initial galling appears to be associated with dry conditions and gall populations decline with rain. Emergence-trap catches show that phylloxera maintain populations on rootstock roots and that these populations disperse above ground. Aerial trap data demonstrated wind dispersal of crawlers and alates. Shielding of canes from soil-emerging phylloxera largely prevented early gall formation. These results suggest alternative testable hypotheses for explaining overwintering of phylloxera in rootstock vineyards.

The life cycle of grape phylloxera is predominantly asexual and may occur on leaves and roots of grapevines (Granett et al., 2001). However, male and female eggs may be laid by alates arising from the asexual populations on roots (radicicoles) (Riley, 1876) or may be laid by non-winged asexual females in leaf galls (gallicoles) (Downie and Granett, 1998). The sexuals from radicicole alates are thought to lay eggs capable of surviving winter when laid on vine canes or trunks above ground. The overwintering egg hatches into the fundatrix in spring, and this individual is thought to be responsible for initiating the gallicole populations on leaves (Davidson and Nougaret, 1921; Riley, 1876). The role of eggs arising from leaf sexuals (Downie and Granett, 1998) is not known but they too may have an overwintering function. Portions of this complex, holocyclic life cycle are bypassed in various parts of the insects' extended geographical range. For example, in viticultural regions of California, gallicoles are generally not found

Received for publication 16 Jan. 2004. Accepted for publication 12 May 2004. We thank M. Andrew Walker, University of California, Davis, James Fisher, USDA-ARS, Corvalis, Oreg., and two anonymous scholars for critically reviewing the manuscript. The research was partially supported by the Fulbright Foundation.

${ }^{1}$ To whom reprint requests should be addressed. e-mail jgranett@ucdavis.edu. above ground overwintering egg, however, are lacking. In addition, observations of the spatially and temporally sporadic distribution of gallicole populations in Hungary stimulated questions about this portion of the life cycle. Granett and Kocsis (2000) studying gallicole populations in a rootstock nursery found that gallicoles were sparse and unevenly distributed in early summer but spread and became more evenly distributed as the season progressed. By the end of the summer, gallicoles were throughout the observation area and if overwintering eggs were being laid, they should have been ubiquitous. Yet the following spring, the populations were sparse and uneven again.

The purpose of our research was to explore temporal distribution of gallicoles and determine how this distribution arose. We sought to test the hypothesis that leaf galls are created by individuals arising from the soil in the spring.

\section{Materials and Methods}

Studies were done in the rootstock nursery and mother vine block of Veszprém University, Georgikon Faculty of Agronomy, Cserszegtomaj (near Keszthely), Hungary, with a long established grape phylloxera infestation. We made observations on two $V$. berlandieri Planch. $\times V$. riparia Michx. cultivars, Teleki $8 \mathrm{~B}$ and Teleki $5 \mathrm{C}$. Both cultivars were head pruned and canes grew up wires arranged at a $45^{\circ}$ angle from the vine head and along a horizontal wire at $2 \mathrm{~m}$ height above the ground. Each vine had five canes which were pruned of side canes at about three-week intervals. Vine rows were clean cultivated.

We counted grape phylloxera galls on canes of Teleki 8B vines in 1999. At intervals from the first leaf at budbreak (1 May 1999) until canes stopped growing (August 1999) we counted the number of grape phylloxera galls on each leaf noting the leaf position with the first leaf on the cane being number one and the leaf at the growing cane tip being the highest number. Observations were made on a single cane on each of 10 randomly selected vines. For each cane we determined the proportion of the total gall count for the season that was

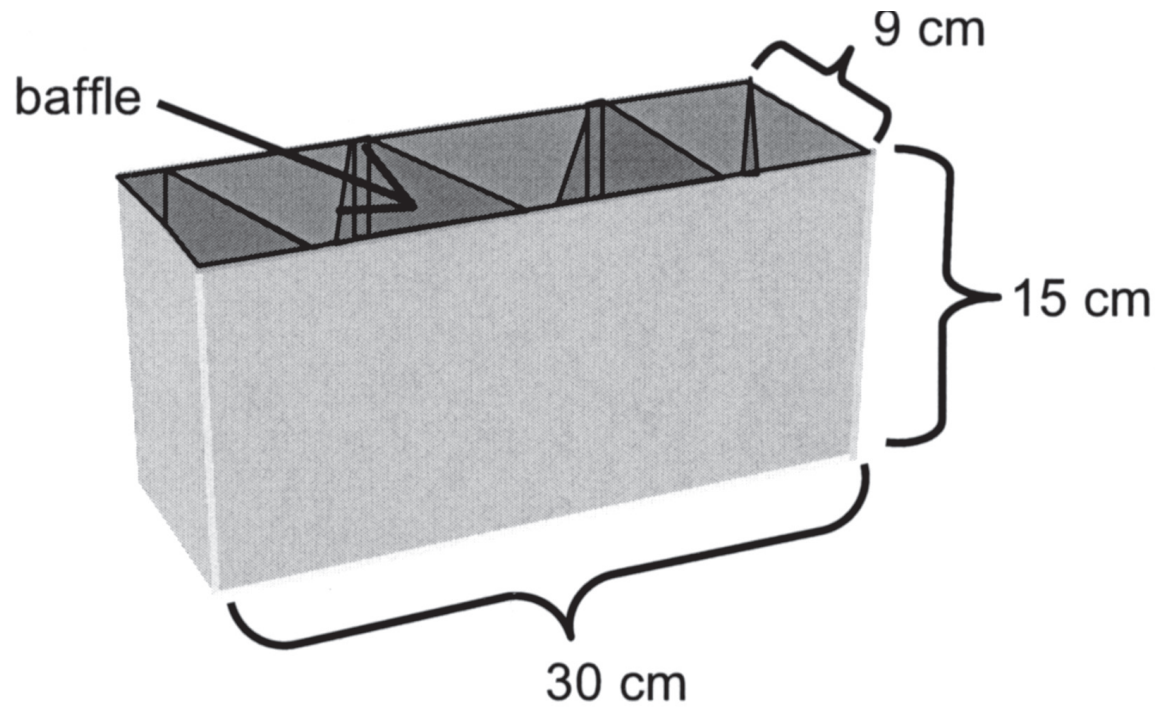

Fig. 1. Emergence traps were constructed of black-painted, 0.5-mm-thick hard plastic with the top covered with a replaceable inward facing adhesive paper (not shown). 
found on each leaf of that cane. Because our observations were made periodically through the season, we were able to estimate the date that each leaf developed by dividing the number of leaf positions by the interval of time since the previous count. We did 5-d averages of the proportion data using canes as replicates and attempted to normalize the data by a power transformation. We ignored galling on side shoots because of their erratic appearance, impermanence due to the normal vineyard management practices, and because they might not be physiologically similar or exposed to the elements in a manner similar to the main canes. Because grape phylloxera galls only develop on newly expanding leaves, our observations of leaves along canes became a calendar of galling. We regressed the total 5 - $d$ average gall values over time to determine a count average for each date. Based on rain data we determined periods of the season that were wet or dry (arbitrarily we set $10 \mathrm{~mm}$ of rain as an indication of a wet period) and determined whether actual gall count values were different from the expected during each rainy or dry period, analyzing results by a chi-square analysis.

From the same row of vines (different vines) we excavated roots from the top about $0.05 \mathrm{~m}^{3}$ of soil within $30 \mathrm{~cm}$ of the trunks and counted phylloxera as first instar nymphs (also known as crawlers; determined as those individuals being roughly the size of eggs), nymphs between the second and fourth instars (individuals larger than first instars and without associated oviposition), and adults (individuals associated by position with recent oviposition). We determined population per gram dry root weight.

We trapped phylloxera emerging from the soil and moving in the air. The soil emergence trap was a box $30 \mathrm{~cm}$ long $\times 9 \mathrm{~cm}$ wide $\times 15$ $\mathrm{cm}$ tall made from hard plastic, about $0.5 \mathrm{~mm}$ thick and spray-painted black (Fig. 1). Inside the box we placed vertically oriented baffles to allow grape phylloxera emerging from the soil to crawl upward. The top of the box was closed with inward facing adhesive paper that was replaced at about 2 -week intervals. The traps were deployed regularly from early spring to late fall at eight locations in a Teleki $5 \mathrm{C}$ row under vines. To count emergence, the adhesive papers were removed from the trap box, covered with clear plastic film and brought to the laboratory where trapped grape phylloxera were identified by form and size, and counted. When grape phylloxera were counted we noted their position relative to the enclosed space of the trap to ascertain whether they were on the portion of the adhesive paper indicating that they had emerged from the soil covered by the trap or on the portion of the adhesive paper outside the trap wall indicating that they could have crawled or blown onto the adhesive paper from outside the trap or come from the soil.

Aerial traps consisted of 6-cm-wide twosided adhesive tape wrapped around a 9-cmdiameter cylinder. These traps were deployed on $1.5-\mathrm{m}$ stakes between vine rows randomly in the vineyard. The adhesive tape was removed at about 2-week intervals and adhering grape phylloxera crawlers and alates were counted.

Lastly, a manipulative exclusion experiment was conducted to determine whether shielding newly growing canes from wind or soil borne grape phylloxera crawlers protected them from galling. Before budbreak on 27 Apr. 2000, three treatments were made on Teleki $5 \mathrm{C}$ vines. For the first treatment, a plastic cone shaped baffle was placed around the vine trunk so that phylloxera crawlers that might be emerging from the soil could not crawl up to the growing cane. The second treatment had a clear plastic sheet around the growing cane so that grape phylloxera crawlers blowing in the wind could not reach the growing cane, but crawlers emerging from the soil could. The third treatment had neither the soil emergence protection nor the wind distribution protection. These treatments were randomly replicated in experimental vines. Formed leaf galls were counted on all test vines

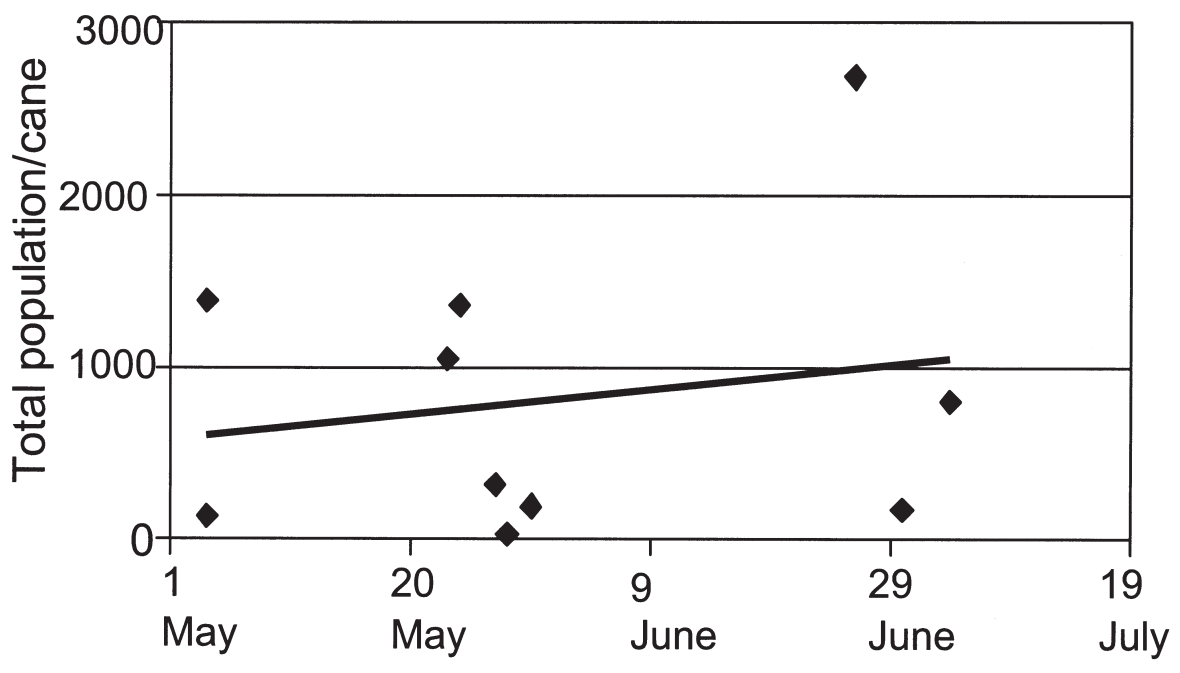

Day of first gall

Fig. 2. Relationship between the total population of phylloxera galls that developed during the growing season on a cane and the date when the first leaf gall appeared on that cane.

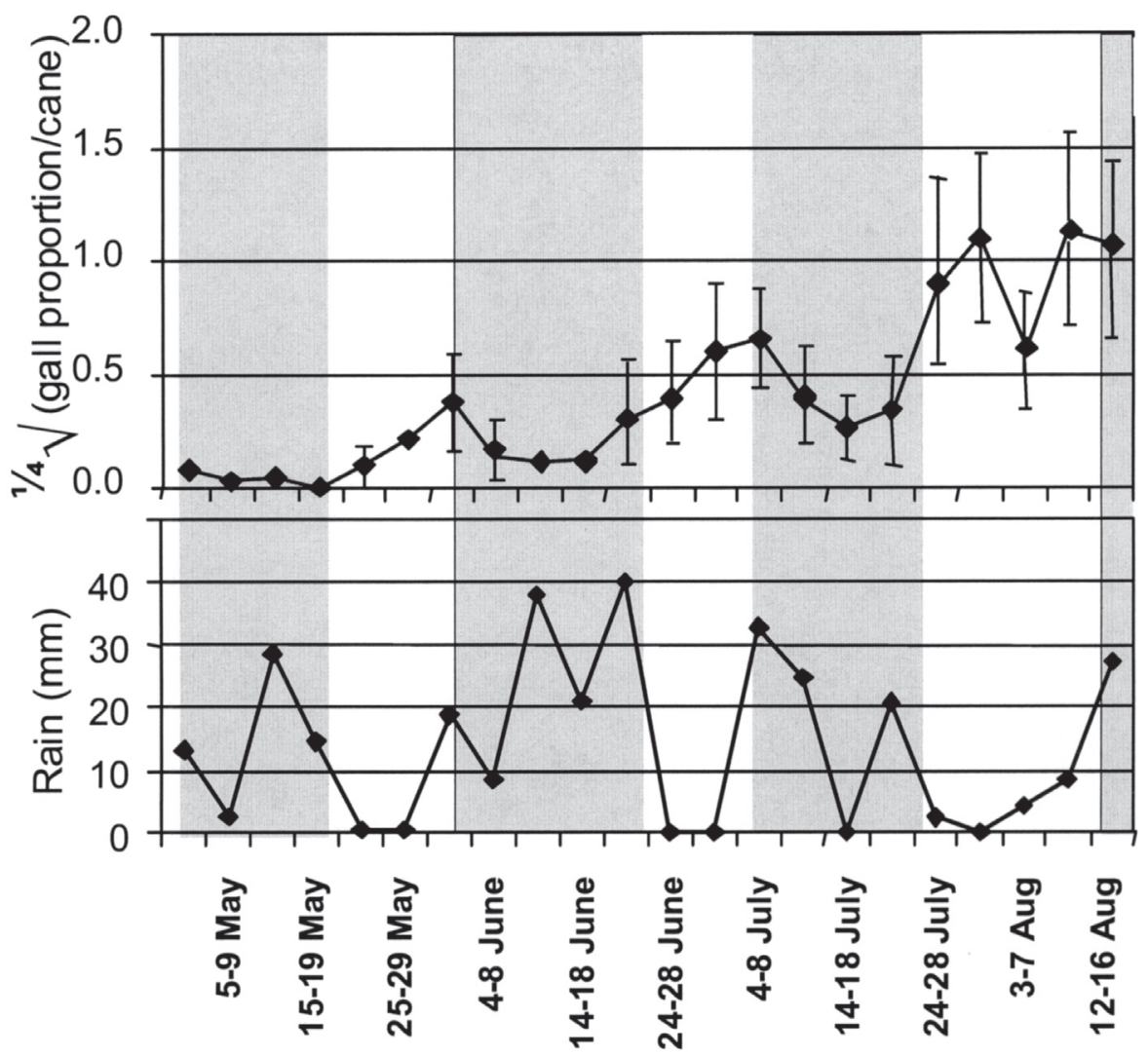

Fig. 3. Mean ( $\pm 95 \%$ C.I.) proportion of total phylloxera galls per leaf per cane for 10 Teleki $8 \mathrm{~B}$ canes. Budbreak occurred about 1 May. Véraison occurred mid August at the termination of the study. Rainfall $(\mathrm{mm})$ for 5-d intervals in the rootstock nursery and mother vine block of Veszprém University, Georgikon Faculty of Agronomy, Cserszegtomaj (near Keszthely), Hungary. 
11 May 2000. We used separate chi-square tests to determine whether each treatment produced results different from the control results.

Monitoring stations at the Veszprém University, Georgikon Faculty of Agronomy provided all weather data.
Results and Discussion

The total numbers of galls that developed per cane for the season were $6.5,50,52,513$, $435,345,145.5,863,105$, and 2268. The total numbers of galls that developed on canes did not regress with the date of the first galls to

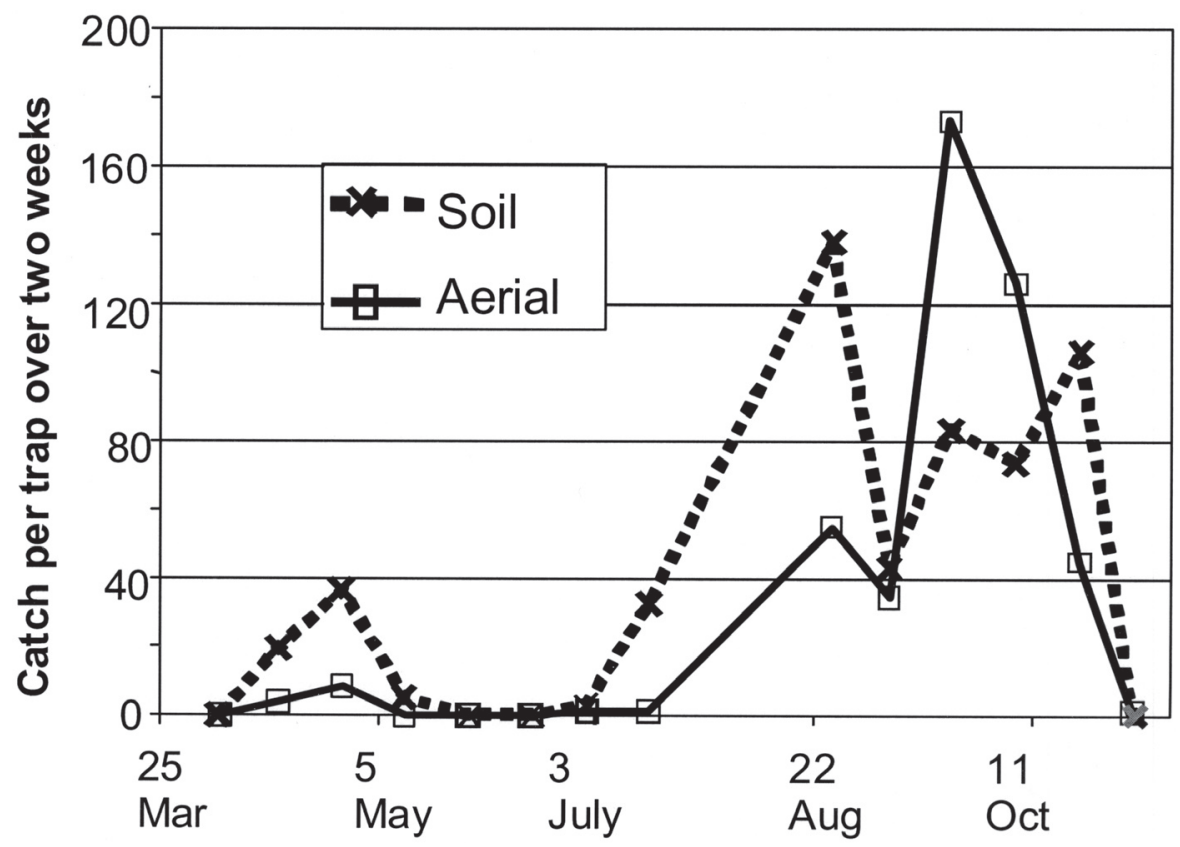

Fig. 4. Soil emergence and aerial trap catch, 2-week average per trap.
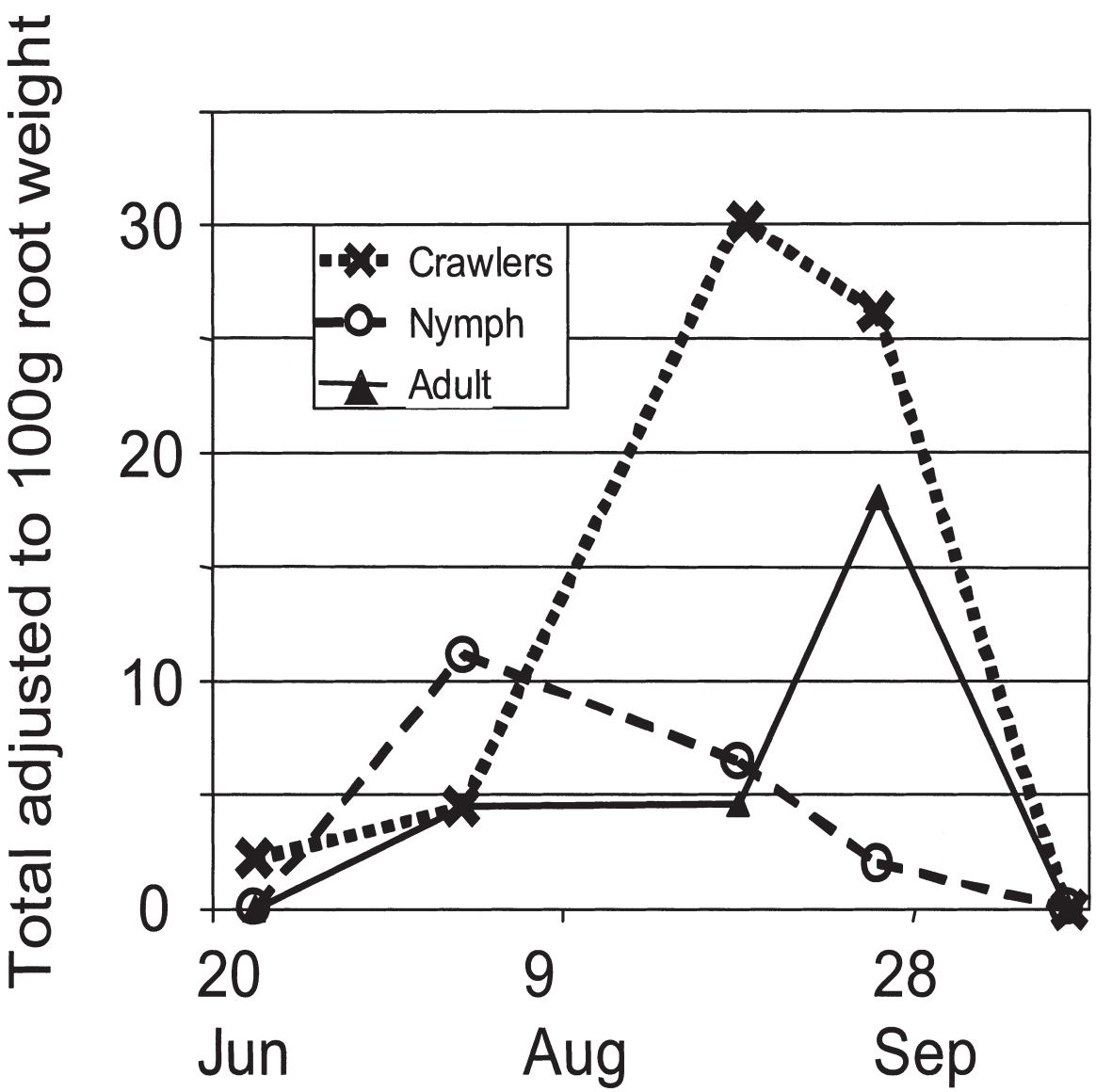

Fig. 5. Population of grape phylloxera crawlers, nymphs, and adults on Teleki 8B roots during Summer 1999. $\operatorname{appear}\left(\mathrm{y}=7.04 \mathrm{x}+584 ; R^{2}=0.035 ;\right.$ Fig. 2$)$. A large population can develop on a cane with a late date of first infestation suggesting that the cane population is less dependent on date of infestation than it is on plant or weather factors. However, the dates when galling first appeared occurred in early May, late May, and late July. These days were characterized by relatively dry weather conditions (Fig. 3).

When gall proportions were averaged by date across all canes, populations did not appear to grow smoothly through the season; there were distinct peaks and valleys of populations (Fig. 3). Galls first occurred at budbreak and large proportions of galls appeared about days $30,60,90$, and 104 . Valleys in galling numbers occurred between these peaks. Though phylloxera populations may have generational times of about $30 \mathrm{~d}$ (Granett et al., 1983), this seems an unlikely cause of the peaks because of generational overlap caused by the relatively long period of oviposition within generations (Granett and Kocsis, 2000). However, periods of rainfall $>20 \mathrm{~mm} / 5 \mathrm{~d}$ correlated with low values for the gall data suggesting rainfall as a limiting factor for gall formation $(\mathrm{df}=5$; chi-square $=0.98 ; p<0.05)$.

Soil emergence- and aerial trap data show initial appearance of grape phylloxera crawlers in late April (Fig. 4) corresponding to the first leaf galls (Fig. 3). Catch of grape phylloxera from the soil and from the air occurred throughout the season. In addition, populations of all stages were observed on roots from June through October (Fig. 5). These results demonstrate that even a strongly resistant grape rootstock such as Teleki $8 \mathrm{~B}$ maintains grape phylloxera radicicoles at least from spring through autumn. These trap data and in situ observations indicate that populations of phylloxera moving in this nursery block were from both roots and leaves and suggest that inocula for leaf infestation could have mixed origins.

The manipulative exclusion experiment showed that when vines were neither shielded from wind movement of crawlers nor shielded from soil emergence, $22 \%$ of test vines became infested (Table 1). This outcome was similar to the situation where wind distribution was prevented but soil emergence was not. On the other hand where soil emergence was prevented with no protection from wind blown individuals, $2 \%$ of the vines were infested. The chi-square analysis indicated that the trunk baffle galling was significantly different from the control (df $=1$; chi-square $=0.0023 ; p<0.05$ ).

Our experiments suggest that leaf galling in the spring is primarily caused by phylloxera emerging from soil. In addition, the initial leaf

Table 1. Prevention of grape phylloxera movement by wind or soil emergence using bags and baffles. The experiment was established 27 April 2000 in Teleki 5C vines and evaluated on 11 May 2000.

\begin{tabular}{lccc}
\hline $\begin{array}{l}\text { Wind } \\
\text { protection }\end{array}$ & $\begin{array}{c}\text { Trunk } \\
\text { baffle }\end{array}$ & $\begin{array}{c}\text { Galled } \\
(\%)\end{array}$ & $\begin{array}{c}\text { Vines } \\
\text { (no.) }\end{array}$ \\
\hline No & Yes & 2 & 41 \\
Yes & No & 19 & 26 \\
No & No & 22 & 27 \\
\hline
\end{tabular}


gall of the year does not appear to come from wind blown or other above ground sources. Therefore, the insects forming the leaf galls at this time must have spent the winter within the soil. Our data do not indicate whether they are offspring of radicicoles or of the sexual generation (i.e. the fundatrix). If the gallicoles are from the sexually arising fundatrix we can hypothesize that they derived nutrients from roots. If this hypothesis is proven correct, this feeding would require a selectable fitness to utilize rootstock roots and might with time lead to rootstock adapted strains.

Previously it was thought that phylloxera could survive the winter above ground as the sexual egg (Riley 1876). In rootstock mother blocks such as this one where the bulk of above ground wood is removed each year, the likelihood of the overwintering form surviving at such sites seems low.

If the gallicoles arise from radicicoles, spatial and temporal patterns for gallicoles will be contingent on the distributions of radicicoles, though other factors (e.g. microclimate, vine physiology) may be critical as well. Resistant rootstock roots tend not to support radicicoles on mature storage roots, but our data show that populations can occur on immature and feeder roots and can arise from the soil. These root populations are low and unevenly distributed and could account for similar distribution patterns of gallicoles in early spring. In addition, the underground winter venue accounts for the lack of vine protection afforded by pruning and vineyard sanitation. Lastly, this underground haven of pre-gallicole phylloxera, whether they are radicicoles or arising from the overwintering egg, suggests the hypothesis that early season and dry weather insecticidal applications to trunks might hinder gallicole formation early in the season, but would not impact pre-gallicoles arising to start new cane infestations during dry periods later in the summer.

\section{Literature Cited}

Davidson, W.M. and R.L. Nougaret. 1921. The grape phylloxera in California. USDA Bul. 903:1-128.

Downie, D. and J. Granett. 1998. A life cycle variation in grape phylloxera Daktulosphaira vitifoliae (Fitch). SW Entomol. 23(1):11-16.

Downie, D.A. 2000. Patterns of genetic variation in native grape phylloxera on two sympatric host species. Mol. Ecol. 9:505-514.

Granett, J., B. Bisabri-Ershadi, and J. Carey. 1983. Life tables of phylloxera on resistant and susceptible grape roots. Entomol. Expt. Appl. 34:13-19.

Granett, J. and L. Kocsis. 2000. Populations of grape phylloxera gallicoles on rootstock foliage in Hungary. Vitis 39(1):37-41.

Granett, J., M. A. Walker, L. Kocsis, and A. D. Omer. 2001. Biology and management of grape phylloxera. Ann. Rev. Entomol. 46:387-412.

Riley, C.V. 1876. The grape phylloxera. 8th annual report of the noxious, beneficial, and other insects of the state of Missouri. 11th Annu. Rpt. State Board Agr. State of Mo. 1875. Regan \& Carter, Jefferson City, Mo. 